\title{
Luteolin sensitizes Fas/FasL - induced apoptosis in HepG2 cells through inhibiting Akt Activation and promoting XIAP Degradation
}

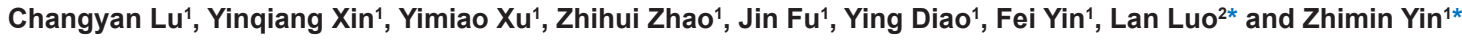

${ }^{1}$ Jiangsu Province Key Laboratory for Molecular and Medicine Biotechnology, College of Life Science, Nanjing Normal University, Nanjing, Jiangsu, P R China

${ }^{2}$ State Key Laboratory of Pharmaceutical Biotechnology, School of Life Sciences, Nanjing University, Nanjing 210093, P R China

\begin{abstract}
Fas, an important cell surface protein of the TNF receptor superfamily that induces apoptosis through binding Fas ligand or anti-Fas antibodies. Unfortunately, not all Fas-expressing cells are sensitive to its stimulus. Therefore it is important to study the mechanisms that counteract the FasL-induced apoptotic process which are still poorly understood. Luteolin, an important flavonoid present in a variety of edible plants, exhibits a wide spectrum of pharmacologic properties such as anticancer, antioxidant, and anti-inflammatory. Furthermore, much more attention has been turned to the chemosensitizing effect of luteolin on cancer cells death. In this study, we found that luteolin synergistically caused the FasL-induced apoptosis in HepG2 cells. Such potentiation was achieved through inhibiting Akt activation and promoting proteasomal degradation of X-linked Inhibitor of Apoptosis Protein (XIAP) which mediated the survival signals and allow the cells to escape from apoptosis in various human cancers.
\end{abstract}

Keywords: Luteolin; Akt; XIAP; Apoptosis

\section{Introduction}

The death receptor Fas, also known as APO-1 or CD95, is a type I transmembrane protein and a member of the TNF receptor superfamily. Its cognate ligand, Fas ligand (FasL), belongs to the TNF family and is type II transmembrane protein of $40 \mathrm{KD}$. Cross-linking of surface Fas molecules by the Fas ligand or agonistic anti-Fas Abs activates apoptotic death programs [1]. Unfortunately, many HCC cells as well as majority tumor cells seem to be relatively resistant to Fas/ FasL-mediated apoptosis [2]. Previous research indicates that serine/ threonine protein kinase $\mathrm{PKB} / \mathrm{Akt}$ protect cells from Fas-induced apoptosis [3,4]. Moreover, the PI3K/Akt control First Trimester Trophoblast cell sensitivity to Fas-induced apoptosis via preventing the ubiquitination and degradation of XIAP [5], suggesting Akt play an important role in Fas/FasL-mediated apoptosis.

Akt, also named protein kinase B (PKB) [6,7], is a serine/threonine protein kinase. Full activation of Akt requires recruitment to the plasma membrane and phosphorylation at $\mathrm{Thr}^{308}$ and $\mathrm{Ser}^{473}$ [8]. Accumulated evidence indicates that Akt and its downstream targets promote cell survival and suppress apoptotic death in a major cell types [9]. Recently reports show that Akt phosphorylates X-linked inhibitor of apoptosis protein (XIAP) at residue serine ${ }^{87}$ and inhibits the ubiquitination and degradation [10].

Flavonoids are natural occurring polyphenolic compounds that are widely distributed in the plant kingdom, displaying a wide range of pharmacologic properties, including anti-inflammatory, antioxidant, anticarcinogenic and anticancer activities [11]. Luteolin, $3^{\prime}, 4$ ',5,7-tetrahydroxyflavone, is a natural occurring flavonoid found in many types of fruits and vegetables. Flavonoids inhibit tyrosine $[12,13]$ and serine kinases [14] via competing with ATP binding [12]. Such action of luteolin was found to be similar to its inhibitory effect on LPS-induced Tyrosine and Akt phosphorylation [15]. Recently, much attention has been paid to the chemosensitizing effect of luteolin. There were reports suggested that luteolin significantly sensitizes TNF, TRAIL and cisplatin-induced apoptosis in various hunman cancer cells [16-19], suggesting the potential therapeutic value of luteolin in cancer therapy. It has also been observed that luteolin is blood-brain barrier permeable, rendering it applicable to the therapy of central nerve system diseases, including brain cancer [20].

Therefore, the aim of this study is to determine if the Akt plays a crucial role in the function of luteolin enhances Fas-mediated apoptosis in HepG2 cells. In this study, we show that luteolin overcomes FasL resistance and synergistically induces apoptosis with FasL in HepG2 cells. This result raises the possibility that the combined treatment with luteolin and FasL might be promising as a new therapy against cancer.

\section{Materials and Methods}

\section{Antibodies and reagents}

Luteolin was purchased from sigma. It was soluted in sterile ethanol at $10 \mu \mathrm{mol} / \mathrm{L}$. The recombinant human Fas Ligand was purchased from $\mathrm{R} \& \mathrm{D}$ systems. It was soluted in sterile PBS containing at least $0.1 \%$ human bovin serum albumin at $10 \mu \mathrm{g} / \mathrm{ml}$. Polyclonal antibodies to Akt, p-Akt $\left(\mathrm{Ser}^{473}\right)$, p-Akt $\left(\mathrm{Thr}^{308}\right)$, procaspase-3, XIAP, and PARP were purchased from Cell Signaling Technology. GAPDH was purchased from KANGCHEN Corporation. The PI3K inhibitor, Wortmannin was purchased from Calbiochem.

\section{Cell culture and transfection}

Human hepatoma HepG2 cells and human hepatocytes L02

*Corresponding authors: Zhimin Yin, College of Life Sciences, Nanjing Normal University, No. 1 Wenyuan Road, Nanjing 210046, PR China, Tel \& Fax: 86-2585891305; E-mail: yinzhimin@njnu.edu.cn

Lan Luo, State Key Laboratory of Pharmaceutical Biotechnology, School of Life Sciences, Nanjing University, Nanjing 210093, PR China, E-mail: lanluo@nju.edu.cn

Received November 05, 2011; Accepted November 25, 2011; Published November 28, 2011

Citation: Lu C, Xin Y, Xu Y, Zhao Z, Fu J, et al. (2011) Luteolin sensitizes Fas/ FasL-induced apoptosis in HepG2 cells through inhibiting Akt Activation and promoting XIAP Degradation. J Carcinogene Mutagene 2:121. doi:10.4172/21572518.1000121

Copyright: (c) $2011 \mathrm{Lu} \mathrm{C}$, et al. This is an open-access article distributed unde the terms of the Creative Commons Attribution License, which permits unrestricted use, distribution, and reproduction in any medium, provided the original author and source are credited. 
are cultured in Dulbecco's modified Eagle's medium (Hyclone) supplemented with $10 \%(\mathrm{v} / \mathrm{v})$ fetal bovine serum (Hyclone), sodium bicarbonate, $100 \mu \mathrm{g} / \mathrm{ml}$ streptomycin and $100 \mathrm{U} / \mathrm{ml}$ penicillin (Hyclone) at $37^{\circ} \mathrm{C}$ in a humidified $5 \% \mathrm{CO} 2$ atmosphere.

Transient transfection was performed with a modified calcium phosphate method or by the LipofectAMINE 2000 reagent (Invitrogen) according to the manufacturer's instructions. In all cases, the total amount of DNA was normalized by addition of empty control plasmids.

\section{Cell viability detection}

Cell viability was determined by using 3-(4,5-dimethylthiazol-2yl)- 2,5-diphenyltetrazolium bromide (MTT) assay. Briefly, HepG2 cells were seeded into the 96 -well plate by $5 \times 10^{4}$ per well and after $24 \mathrm{~h}$, cells were treated with various concentrations of luteolin, FasL (60ng/ $\mathrm{ml})$, or FasL $(60 \mathrm{ng} / \mathrm{ml})$ plus luteolin for $24 \mathrm{~h}$ respectively. Then, the cells were incubated with $5 \mathrm{mg} / \mathrm{ml}$ MTT working solution for $4 \mathrm{~h}$ at $37^{\circ} \mathrm{C}$ followed by treatment with $10 \mu \mathrm{l}$ DMSO to dissolve the crystals. Cell viability was detected under an Elx 800 Universal Microplate Reader (BIO-TEK, INC) by examining the absorbance at $570 \mathrm{~nm}$.

\section{Immunoprecipitation and Immunoblotting analysis}

HepG2 Cells were washed twice with ice-cold PBS, and solubilized in lysis buffer containing $20 \mathrm{mM}$ Tris ( $\mathrm{pH}$ 7.5), $135 \mathrm{mM} \mathrm{NaCl}, 2 \mathrm{mM}$ ethylenediaminetetraacetic acid(EDTA), $2 \mathrm{mM}$ dithiothreitol (DTT), $25 \mathrm{mM}$ b-glycerophosphate, $2 \mathrm{mM}$ sodium pyrophosphate, $10 \%$ glycerol, $1 \%$ Triton X-100, $1 \mathrm{mM}$ sodium orthovanadate, $10 \mathrm{mM} \mathrm{NaF}$, $10 \mathrm{lg} / \mathrm{ml}$ aprotinin, $10 \mathrm{lg} / \mathrm{ml}$ leupeptin, and $1 \mathrm{mM}$ phenylmethylsulfonyl fluoride (PMSF) supplemented with complete protease inhibitor cocktail at $4^{\circ} \mathrm{C}$. Lysates were centrifuged $(15000 \times \mathrm{g})$ at $4^{\circ} \mathrm{C}$ for $15 \mathrm{~min}$. Protein $(0.5 \mathrm{mg})$ were immunoprecipitated with indicated antibodies $(0.5 \mu \mathrm{g})$ respectively. The precleared Protein A/G PLUS-agarose beads (Santa Cruz Biotechnology) or protein agarose beads (Roche Applied Science) were incubated with immunocoplexes for $2 \mathrm{~h}$ and washed four times with lysis buffer. The immunoprecipitates were subjected to SDSPAGE followed by transferring onto polyvinylidene difluoride (PVDF) (Roche Applied Science) or nitrocellulose membranes (Hybond-C, Amersham Biosciences). The antibody-antigen complexes were visualized by the LI-COR Odyssey Infrared Imaging System according to the manufacturer's instruction using IRDye800 flurophoreconjugated antibody (LI-COR Biosciences, Lincoln, NE) or using TMB immunoblotting system (Promega). Quantification was directly performed on the blot using the LI-COR Odyssey Analysis software.

\section{TUNEL assay}

TUNEL assay was performed in HepG2 cells by using Guava TUNEL Kit according to the manufactuerer's instructions. The cells were detected on a Guava EasyCyte ${ }^{\mathrm{TM}}$ System, and the data were analysed ueing Guava TUNEL. Software (Guava Technologies, Hayward, CA, USA)

\section{MultiCaspase apoptosis detection}

MultiCaspase apoptosis detection (Guava) is an accurate method for determining the number of cells in various stages of the poptotic pathway. Fluorochrome-conjugated inhibitor of caspases called sulforhodamine-valyl-alanyl-aspartyl-fluoromethylketone (SR-VADFMK) and cell impermeant dye 7-Aminoactinomycin (7-AAD) were used to distinguish non-apoptotic live cells, early/mid apoptotic stage cells, late apoptotic/dying cells, and dead cells. The assay was on the basis of the manufacturer's protocol and stained cells were analyzed on a Guava EasyCyteTM System.

\section{RT-PCR analysis}

Total RNA was extracted with Trazol reagent (Gibco, USA) as described by the manufacturer. RT-PCR was performed using the Access RT-PCR Introductory System (Promega) with indicated primers (XIAP: sense GAAGACCCTTGGGAACAACA, anti-sense CGCCTTAGCTGCTCTTCAGT [21]; $\beta$-actin: sense TCATGAGGTAGTCAGTCAGG, antisense TGACCCAGATCATGTTTGAG). PCR was performed for 30 cycles in $25 \mu \mathrm{l}$ of reaction mixture. PCR products were resolved on $1.2 \%$ agarose gels and stained with ethidium bromide. $\beta$-actin was utilized as a housekeeping gene where indicated.

\section{Statistical analysis}

All experimental data were expressed as mean \pm SEM. Each value was the mean of two or three independent experiments in each group. Student's t-test and one-way analysis of variance (ANOVA) were used to determine the statistical significance of data.

\section{Results}

\section{Luteolin sensitizes FasL-induced death in HepG2 cells}

Majority of cancer cells that express CD95, however, do not always correlate with sensitivity to CD95-induced apoptosis. There are reports shown that luteolin was able to enhance TNF and TRAIL mediated apoptosis $[15,16]$. In this study, HepG2 cells were found to be resistant to FasL-induced cell death at different concentrations (Figure 1A), which was also one of tumor necrosis factor superfamily. We next tested the combined effect of luteolin and FasL. Interestingly, evident cell death occurred in dose-dependent manner after 24h (Figure 1B). These results indicate that luteolin strongly enhance FasL-induced death in HepG2 cells.

\section{The effect of luteolin on FasL-initiated caspase cascade}

Caspase activation is the central machinery in apoptosis, and FasLinduced apoptosis is mainly executed by cell death receptor pathway initiating from caspase- 8 activation [22], and ultimately activate the effector caspase-3. In this study, we examined the role of luteolin in FasL-initiated caspase cascade. Here we found that caspase- 8 changed evidently treated with Luteolin alone in a dose dependent manner (Figure 2A). Similar pattern of caspase- 3 activation was also observed (Figure 2A). Although luteolin at $30 \mu \mathrm{M}$ or FasL at $60 \mathrm{ng} / \mathrm{ml}$ alone did not cause obvious change in caspase 3 and PARP, the combination treatment with luteolin and FasL led to the complete cleavage of caspase-3 and PARP (Figure 2B). Furthermore, we want to know if the sequence of treatment would affect the cell death. Figure $2 \mathrm{C}$ shows there were no obvious difference of the sensitization among the three ways which were luteolin pre-treatment, luteolin post-treatment and luteolin pari-treatment.

We then used caspase inhibitor $\mathrm{z}$-VAD-fmk (a pan caspase inhibitor) to confirm the role of the caspase cascade in apoptosis induced by luteolin and FasL. The general caspase inhibitor completely blocked PARP cleavage and caspase 8, 3 activation in cells treated with luteolin and FasL (Figure 2D). In some cells, FasL mediates apoptotic cell death via the mitochondrial pathway via caspase 8-mediated Bid 
Citation: Lu C, Xin Y, Xu Y, Zhao Z, Fu J, et al. (2011) Luteolin sensitizes Fas/FasL-induced apoptosis in HepG2 cells through inhibiting Akt Activation and promoting XIAP Degradation. J Carcinogene Mutagene 2:121. doi:10.4172/2157-2518.1000121

A

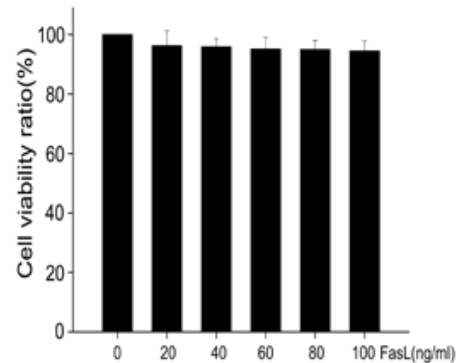

B

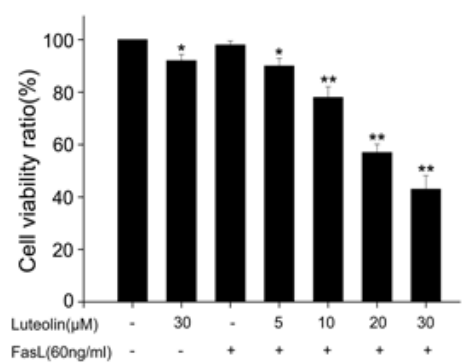

Figure 1: Luteolin overcomes the resistance of FasL-mediated cell death in HepG2 cells. (A) HepG2 cells were treated with various concentrations of FasL for 24h. (B) HepG2 cells were pretreated with indicated concentrations of luteolin for $2 \mathrm{~h}$, followed by treatment with $60 \mathrm{ng} / \mathrm{ml}$ FasL for another $22 \mathrm{~h}$. Cells viability was determined by MTT assay as described in Material and Methods. Cells viability without treatment was taken as $100 \%$. Data are means \pm S.D. of three independent experiments.

A

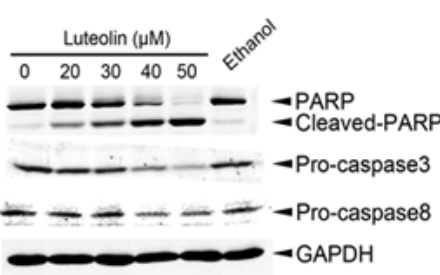

C

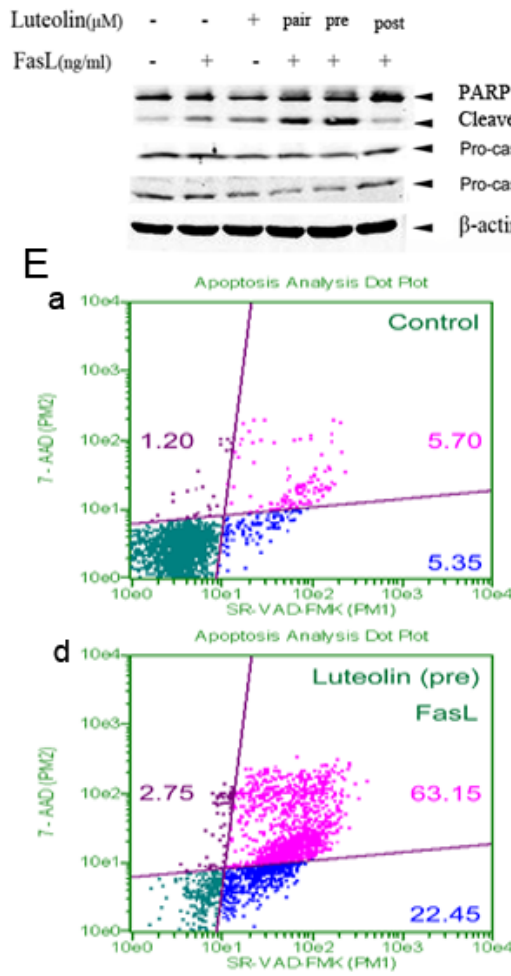

B

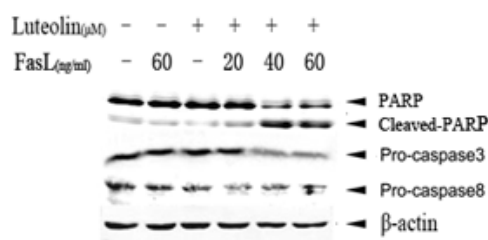

D

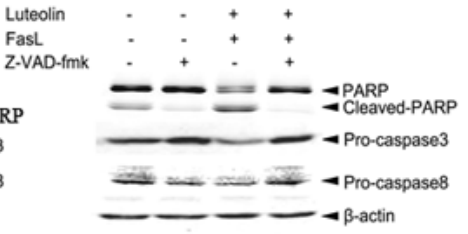

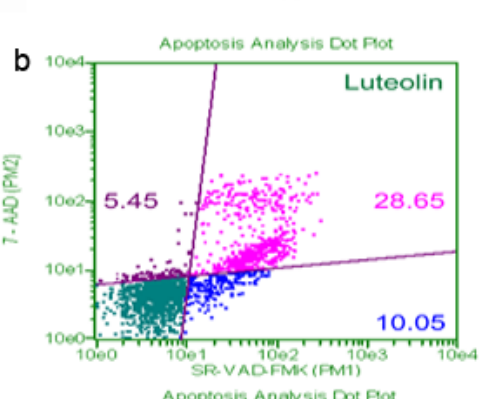

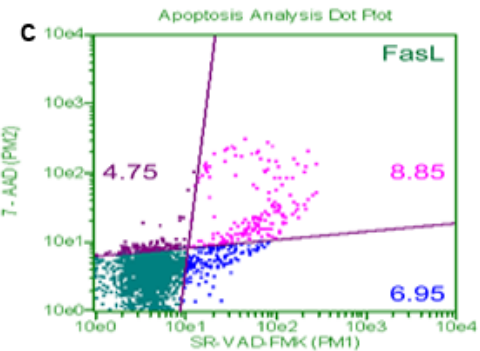

Figure 2: The effect of luteolin on FasL-initiated caspase cascade. (A) HepG2 cells were treated with $20 \mu \mathrm{M}, 30 \mu \mathrm{M}, 40 \mu \mathrm{M}, 50 \mu \mathrm{M}$ luteolin for $16 \mathrm{~h}$, and using the solvent of luteolin (DMSO) as negative control. Cells were collected and analysed by western blot using the specific anti-PARP, caspase 8 and caspase 3 antibodies. (B) HepG2 cells were pretreated with $30 \mu \mathrm{M}$ luteolin for $2 \mathrm{~h}$, and then treated with viriouse concentrations of FasL for another $22 \mathrm{~h}$. Cells lysates were detected by immunoblot analysis using indicated antibodies. (C) HepG2 cells were pretreated, post-treated with $30 \mu \mathrm{M}$ luteolin for $2 \mathrm{~h}$, and pari-treated luteolin and FasL (60ng/ml)

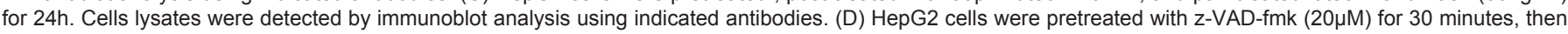
cells were treated with luteolin $(30 \mu \mathrm{M} \times 24 \mathrm{~h})$ and FasL $(60 \mathrm{ng} / \mathrm{ml} \times 22 \mathrm{~h})$. Cells lysates were collected for detection of caspase 3 and caspase 8 cleavage by immunoblot analysis. (E) HepG 2 cells were pretreated, post-treated with $30 \mu \mathrm{M}$ luteolin for $2 \mathrm{~h}$, and pari-treated luteolin and FasL (60ng/ml) for $24 \mathrm{~h}$. Cells lysates were detected by MultiCaspase apoptosis assay. 
Citation: Lu C, Xin Y, Xu Y, Zhao Z, Fu J, et al. (2011) Luteolin sensitizes Fas/FasL-induced apoptosis in HepG2 cells through inhibiting Akt Activation and promoting XIAP Degradation. J Carcinogene Mutagene 2:121. doi:10.4172/2157-2518.1000121

cleavage [23]. We also conducted MultiCaspase apoptosis detection for measuring luteolin pre-treatment, luteolin post-treatment and luteolin pari-treatment induced apoptosis in HepG2 cells (Figure 2E). According to the results we could say that luteolin alone-induced caspases activation was $38.7 \%$, the combination of luteolin with FasL induced caspases activation was $85.6 \%$. Therefore, it is believed that luteolin, FasL have synergistic effect on HepG2 cells death and luteolin sensitizes FasL-induced apoptosis mainly by the cell death receptor pathway.

\section{The inactivation of Akt contributes to sensitized cell apoptosis}

Akt play an important role in both cell survival and the inhibition of apoptosis. Inhibition of the phosphorylated-Akt enhances the sensitivity of Fas-mediated apoptosis in various human cancers [24]. Data show that the reduction of Akt protein level is mediated by luteolin in dose dependent way (Figure 3A). To determine whether luteolin could inactivate Akt, HepG2 cells were treated with luteolin at various time points, and cellular protein extracts were prepared to analyze for phosphor-Akt $\left(\mathrm{Ser}^{473}, \mathrm{Thr}^{308}\right)$ and total Akt proteins by immunoblot assays. As shown in Figure 3B, the level of phosphorylated Akt at $\mathrm{Ser}^{473}$ not at $\mathrm{Thr}^{308}$ (data not show) was down-regulated by low concentration of luteolin in time-dependent manner, whereas the level of total Akt was remained unchanged after low dose of luteolin treatment. Results also show that luteolin can attenuate Akt activation in cells treated with FasL (Figure 3 C). Morover, in control cells, most of the cells underwent apoptosis after luteolin and FasL treatment, while in contrast, most Akt-transfected cells remained alive (Figure 3D). The dates indicated that luteolin sensitized FasL-mediated apoptosis by inhibiting Akt activation.

\section{Down-regulation of $\mathrm{X}$-linked inhibitor of apoptosis protein (XIAP) contributes to sensitization effect of luteolin on FasL- induced apoptosis}

In FasL-induced hepatocyte apoptosis, XIAP is a critical attenuator via inhibition of the caspase cascade [25]. There was also report demonstrate that XIAP is a physiological substrate of Akt [26]. In order to identify the molecular mechanisms which may be involved in the sensitization activity of luteolin, we examined whether cotreatment of FasL with luteolin can influence the protein levels of XIAP proteins. Data show that significantly decreased of XIAP was noted in cells treated with luteolin and FasL in a time and dose dependent way (Figure $4 \mathrm{~A}$ and $4 \mathrm{~B}$ ).

To confirm the role of Akt in XIAP stability and possible mechanisms involved, we further tested the effect of wortmannin on XIAP protein level in cells treated with FasL. The effect of luteolin on Akt phosphorylation was comparable with that of wortmannin, a known Akt inhibitor. As shown in Figure 4C, low dose of luteolin inhibited Akt phosphorylation on $\mathrm{Ser}^{473}$, without altering total Akt levels, which is similar to the effect of wortmannin. This effect could be abolished by transfecting the cells with wild-type Akt plasmid. XIAP protein show a significant decline in nontransfected cells while was stable in Akt-transfected cells (Figure 4D). These data indicate that XIAP as a substrate of Akt involved in the sensitization of luteolin on FasL-mediated apoptosis.

\section{Luteolin promoting XIAP Protein Degradation}

To elucidate the molecular mechanism involved, we first measured the XIAP mRNA level using RT-PCR. Figure 5A showed
A

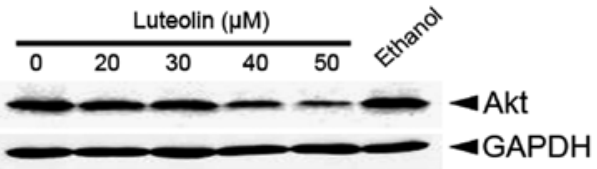

C

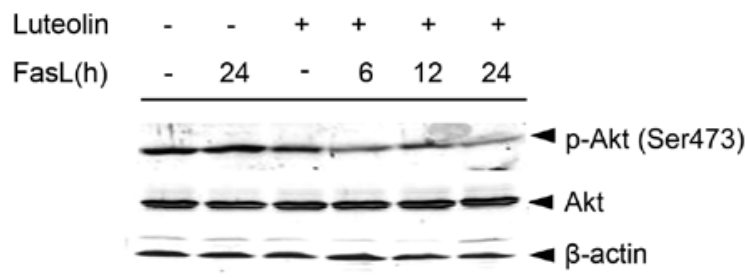

B

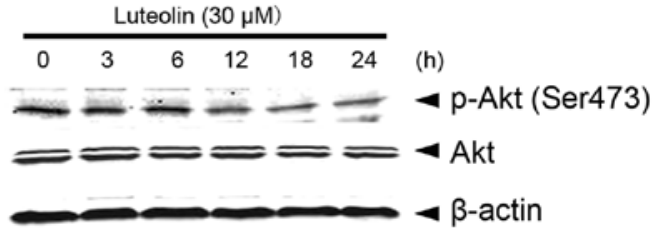

D

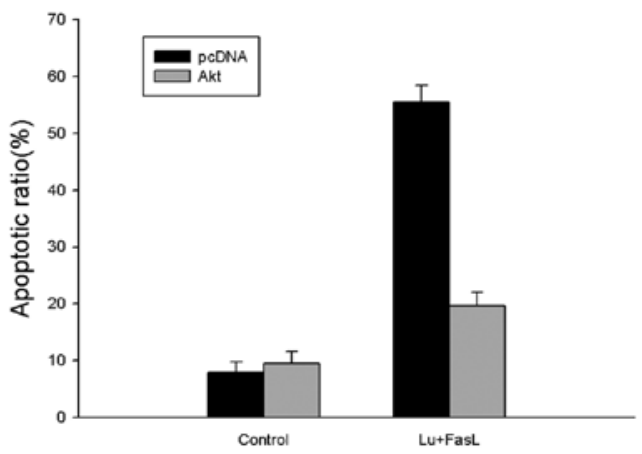

Figure 3: The inactivation of Akt contributes to sensitized cell apoptosis. (A) HepG2 cells were treated with $20 \mu \mathrm{M}$, $30 \mu \mathrm{M}, 40 \mu \mathrm{M}, 50 \mu \mathrm{M}$ luteolin for $16 \mathrm{~h}$. Cells lysates were detected by immunoblot analysis using indicated antibodies. (B) HepG2 cells were pretreated with luteolin as low as $30 \mu \mathrm{M}$ for $24 \mathrm{~h}$. Cells lysates were detected by immunoblot analysis using indicated antibodies. (C) HepG2 cells were pretreated with $30 \mu \mathrm{M}$ luteolin for $2 \mathrm{~h}$, followed by treatment with Fas $(60 \mathrm{ng} / \mathrm{ml}$ ) for $3,6,12,24 \mathrm{~h}$. Cells lysates were detected by immunoblot analysis using indicated antibodies. The content of $\beta$-actin was used as a loading control. (D) HepG2 cells were transiently transfected with pcDNA and wt-Akt, after $24 \mathrm{~h}$, the cells were treated with luteolin $(30 \mu \mathrm{M} \times 24 \mathrm{~h})$ followed by FasL $(60 \mathrm{ng} / \mathrm{ml} \times 22 \mathrm{~h})$. Cell lysate was used for Tunel assay. 
Citation: Lu C, Xin Y, Xu Y, Zhao Z, Fu J, et al. (2011) Luteolin sensitizes Fas/FasL-induced apoptosis in HepG2 cells through inhibiting Akt Activation and promoting XIAP Degradation. J Carcinogene Mutagene 2:121. doi:10.4172/2157-2518.1000121

Page 5 of 7

that either luteolin, FasL, or their combined treatment did not alter the XIAP mRNA level up to 24 hours, indicating that the XIAP is mainly regulated post-transcriptionally. Then, we tested the effects of proteasome inhibitors on XIAP protein level. As shown in Figure 5B, MG132 completely abolished the XIAP down-regulation induced by luteolin and FasL. The above results clearly showed that luteolin and FasL promote XIAP proteasomal degradation.

A

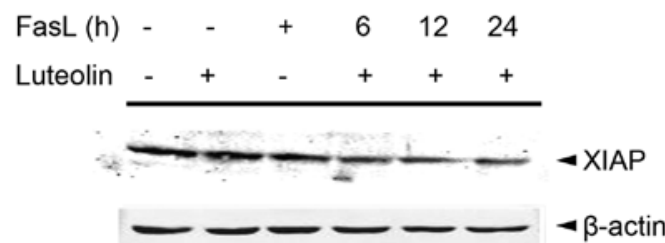

C

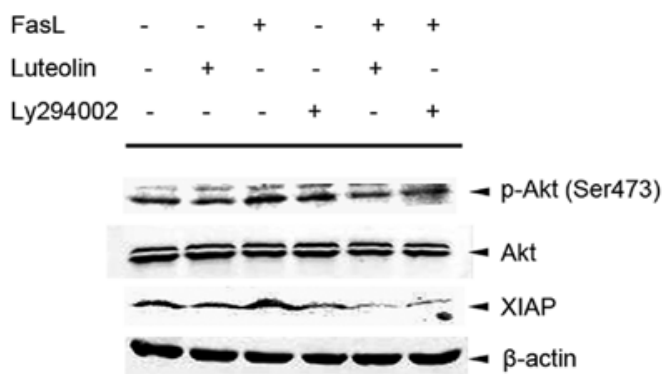

The side effect of chemotherapeutic agents on normal cells is a major problem during clinical treatment. It has been reported that the clinical use of FasL for cancer treatment is still being a limitation given the potential severe toxicity [27]. Therefore, we used normal human Liver cells (L02) as a model. The combination of luteolin and FasL did not induced apoptosis in L02 cells, although it markedly induced apoptosis in HepG2 cells (Figure 5C).
B

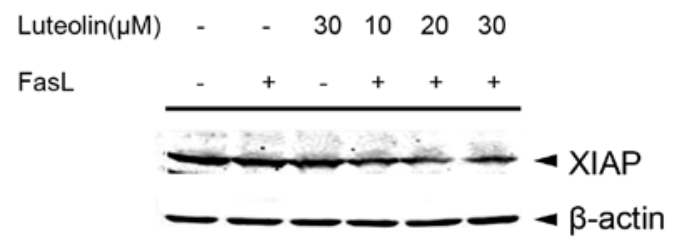

$\mathrm{D}$

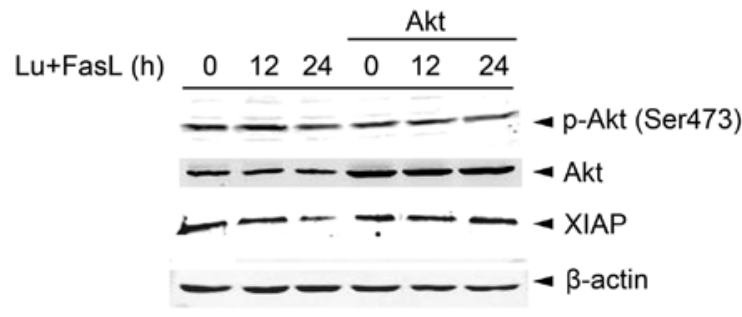

Figure 4: Down-regulation of X-linked inhibitor of apoptosis protein (XIAP) contributes to sensitization effect of luteolin on FasL-induced apoptosis. (A) HepG2 cells were pretreated with $30 \mu \mathrm{M}$ luteolin for $2 \mathrm{~h}$, followed by treatment with FasL $(60 \mathrm{ng} / \mathrm{ml})$ for $3,6,12,24 \mathrm{~h}$. Cells lysates were detected by immunoblot analysis using indicated antibodies. (B) HepG2 cells were pretreated with $10 \mu \mathrm{M}, 20 \mu \mathrm{M}, 30 \mu \mathrm{M}$ luteolin for $2 \mathrm{~h}$, then treated with $60 \mathrm{ng} / \mathrm{ml}$ Fas $\mathrm{L}$ for another $24 \mathrm{~h}$. Cells lysates were detected by immunoblot analysis using indicated antibodies. (C) HepG2 cells were pretreated with Wortmannin $(20 \mu \mathrm{M})$ for 30 minutes, followed by treatment with the combination of luteolin $(30 \mu \mathrm{M} \times 24 \mathrm{~h})$ and FasL $(60 \mathrm{ng} / \mathrm{ml} \times 22 \mathrm{~h})$. Cells lysates were collected for detection of XIAP, p-Akt ${ }^{308}$ and total Akt by Western blot. (D) HepG2 cells were transiently transfected with wt-Akt, after 24 hours, the cells were treated with luteolin $(30 \mu \mathrm{M} \times 24 \mathrm{~h})$ followed by FasL $(60 \mathrm{ng} / \mathrm{ml} \times 22 \mathrm{~h})$. The cells were collected for analysis by western blot using Akt, p-Akt, XIAP antibody. The content of $\beta$-actin was used as a loading control.

A

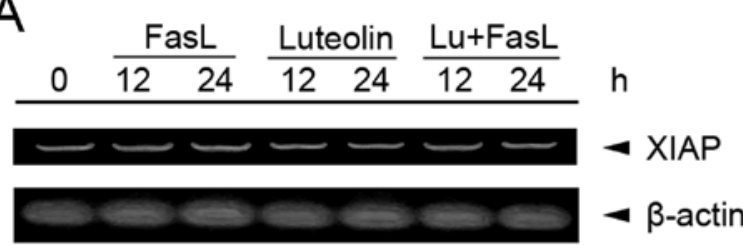

B

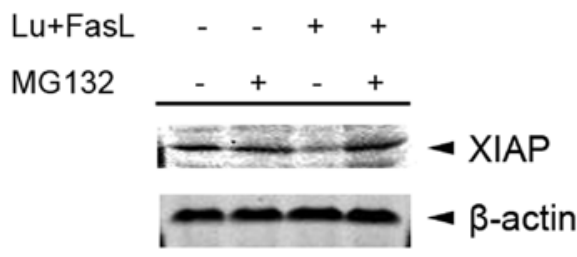

C

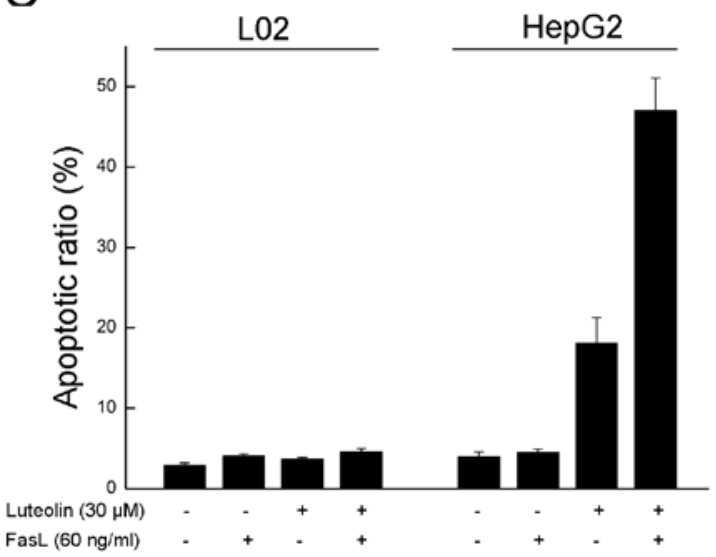

Figure 5: Luteolin promoting XIAP Protein Degradation. (A) HepG2 cells were treated with luteolin (30 $\mu \mathrm{M})$, FasL (60ng/ml) and the both for 12, $24 \mathrm{~h}$. Total RNA was isolated and RT-PCR was performed. XIAP mRNA levels were measured with $1.2 \%$ agarose gels stained with EtBr, and $\beta$-actin mRNA was used as control. (B) HepG2 cells were pretreated with proteasome inhibitor MG132 $(20 \mu \mathrm{M})$ for 1 hour, followed by combined treatment with luteolin $(30 \mu \mathrm{M} \times 24 \mathrm{~h})$ and FasL $(60 \mathrm{ng} / \mathrm{ml} \times 22 \mathrm{~h})$. XIAP protein level was determined by Western blotting. (C) HepG2 cells and L02 cells were treated with luteolin, FasL alone and combination with luteolin ( $30 \mu \mathrm{M} \times 24 \mathrm{~h})$ and FasL $(60 \mathrm{ng} / \mathrm{ml} \times 22 \mathrm{~h})$. Cell lysate was used for Tunel assay. 
Citation: Lu C, Xin Y, Xu Y, Zhao Z, Fu J, et al. (2011) Luteolin sensitizes Fas/FasL-induced apoptosis in HepG2 cells through inhibiting Akt Activation and promoting XIAP Degradation. J Carcinogene Mutagene 2:121. doi:10.4172/2157-2518.1000121

\section{Discussion}

Luteolin is a flavonoid widely distributed in the plant kingdom. It has been well documented the anticancer property of luteolin. Recent research suggests that luteolin may be used to sensitize cancer cells to the cytotoxic effects of some anticancer agents [28]. Thus, it is not inconceivable that a solution for the cytotoxicity problem will be found. Here, we provide important insights for the understanding of the molecular mechanisms involved in the sensitizing effect of luteolin on Fas-induced apoptosis. In the present study, we demonstrated that luteolin is able to increase the sensitivity of cancer cells for Fasmediated apoptosis, but not to the normal human liver cells (L02). The down-regulation of XIAP via inhibiting the activation of the protein kinase PKB contributes to the enhancement effect of luteolin on Fasinduced apoptosis.

The serine/threonine kinase Akt is well known to be an important node in the survival of cells by regulating the relevant substrates. Moreover, an Akt specific inhibitor may be useful in combination with other anticancer agents or radiation to overcome resistance to chemo- or radiotherapy [29]. Angeliki xagorari et al. found that luteolin inhibited LPS-induced phosphorylation of Akt [14]. Evidence suggests that activation of Akt protects cells from Fas-mediated apoptosis [2]. In this study, we found that high concentrations of luteolin can down-regulate the total protein level of Akt (Figure 3A), while low concentrations of luteolin has no effect on Akt protein level but decrease FasL-induced the phosphorylation of Akt in HepG2 cells (Figure 3B,C). Then overexpression of wild-type Akt rescues HepG2 cells from the apoptosis induced by luteolin and FasL (Figure 3D).

Evidently, luteolin, via inhibition of Akt activation, infuences downstream effectors of apoptosis. It has been noted that Akt controls First Trimester Trophoblast cell sensitivity to Fas-induced apoptosis by regulating XIAP expression [26]. Our present study indicated that XIAP protein level was significantly down-regulated by combined treatment with luteolin and TRAIL (Figure 4A,B). More importantly, the decrease of XIAP protein level is contributed to the inhibiting Akt activation by luteolin. This finding was consistent with the preceding report. Such a hypothesis was further suported by the fact that overexpression of Akt protein reversed the decrease of XIAP protein level and the phosphorylation of Akt (Figure 4D).

It has previously been shown that Akt protects XIAP from ubiquitination and degradation depends on phosphorylation serine 87 of XIAP [26]. It has also been reported that XIAP is a considerable attenuator of Fas-mediated mouse hepatocyte apoptosis. We further examined the possible mechanisms cantributing to the reduced XIAP protein level in cells treated with luteolin and FasL. Because no changes were found on the XIAP mRNA level (Figure 5A). We went on to test whether luteolin and FasL promote XIAP proteasomal degreadation, the proteasome inhibitors offered complete protection against XIAP degradation in HepG2 cells treated with luteolin and FasL (Figure 5B). It is thus believed that the decreased XIAP protein level is mediated by proteinsomal degradation, a process crucial for deciding the susceptibility to apoptosis induced by luteolin and FasL in cancer cells.

Evidences demonstrated that anti-Fas antibodies, rFasL reduce the growth of transplanted solid tumors in vivo experiments in mice and also cause severe damage to the mouse liver at the same time [30]. Therefore, liver injury induced by this agent determined the limitation of their application. In this study, we found that luteolin enhance FasL- induced apoptosis in HepG2 cells, while the L02 cells can be exemped from the cytoxic effects at a sufficient dose level. (Figure 5C) It may therefore be possible that luteolin could widen the therapeutic window, allowing cancer cells killing while protecting liver cells.

\section{Acknowledgments}

We particularly thank Dr.Gang Pei, Dr. Sangwon F. Kim and Dr. Ze'ev Ronai for providing partial constructs used in this study. This work was supported by grants from the National Nature Science Foundation of China (Nos. 81172798 81072433 and 31071000) and A Project Funded by the Priority Academic Program Development of Jiangsu Higher Education Institutions (No. 164320H106)

\section{References}

1. Wallach D, Varfolomeev E, Malinin N, Goltsev YV, Kovalenko A et al. (1999) Tumor necrosis factor receptor and Fas signaling mechanisms. Annu. Rev Immunol 17: 331-367.

2. El Bassiouny AE, El-Bassiouni NE, Nosseir MM, Zoheiry MM, El-Ahwany EG et al. (2008) Circulating and hepatic Fas expression in HCV-induced chronic liver disease and hepatocellular carcinoma. Medscape J Med 10: 130.

3. Häusler P, Papoff G, Eramo A, Reif K, Cantrell DA, et al. (1998) Protection of CD95-mediated apoptosis by activation of phosphatidylinositide 3-kinase and protein kinase B. Eur J Immuno I28: 57-69.

4. Osaki M, Kase S, Adachi K, Takeda A, Hashimoto K, et al. (2004) Inhibition of the PI3K-Akt signaling pathway enhances the sensitivity of Fas-mediated apoptosis in human gastric carcinoma cell line, MKN-45. J Cancer Res Clin Oncol 130: 8-14

5. Straszewski-Chavez SL, Abrahams VM, Aldo PB, Romero R, Mor G (2010) AKT controls First Trimester Trophoblast cell sensitivity to FAS-mediated apoptosis by regulating XIAP expression. Biolreprod 146-152

6. Bellacosa A, Testa JR, Staal SP, Tsichlis PN (1991) A retroviral oncogene $\mathrm{AKT}$,encoding a serine-threonine kinase containing an $\mathrm{SH} 2$-like region. Science 254: 274-277.

7. Coffer PJ, and Woodgett JR (1991) Molecular cloning and characterization of a novel putative protein-serine kinase related to the CAMP-dependent and protein kinase C families. Eur J Biochem 201: 475-481.

8. Stephens L, Anderson K, Stokoe D, Erdjument-Bromage H, Painter GF et al. (1998) Protein kinase B kinases that mediate phosphatidylinosito 3,4,5-trisphosphate-dependent activation of protein kinase B. Science 279 : 710-714.

9. Datta SR, Brunet A, Greenberg M E (1999) Cellular survival: a play in three Akts. Genes Dev 13: 2905-2927.

10. Dan HC, Sun M, Kaneko S, Feldman RI, Nicosia SV, et al. (2004) Ak Phosphorylation and Stabilization of X-linked Inhibitor of Apoptosis Protein (XIAP). JBC 279: 5405-5412.

11. Ross JA, Kasum CM (2002) Dietary flavonoids: bioavailability,metabolic effects, and safety. Annu Rev Nutr 22: 19-34.

12. Cunningham B, Threadgill M, Groundwater P, Dale I and Hickman J (1992) Synthesis and biological evaluation of a series of flavones designed as inhibitors of protein tyrosine kinases. Anticancer Drug Des 7: 365-384.

13. Graziani Y, Erikson E, Erikson RL (1983) The effect of quercetin on the phosphorylation of the Rous sarcoma virus transforming gene product in vitro and in vivo. Eur J Biochem 135: 583-589.

14. Gamet-Payrastre L, Manenti S, Gratacap MP, Tulliez J, Chap H, et al. (1999) Flavonoids and the inhibition of PKC and PI3-kinase. Gen Pharmaco I32: 279286

15. Xagorari A, Papapetropoulos A, Mauromatis A, Economou M, Fotsis T, et al (2001) Luteolin inhibits an endotoxin-stimulated phosphorylation cascade and proinflammatory cytokine production in macrophages. JPET 181-187.

16. Shi RX, Ong CN, Shen HM (2004) Luteolin sensitizes tumor necrosis factor-ainduced apoptosis in human tumor cells. Oncogene 23: 7712-7721.

17. Shi RX, Ong CN, Shen HM (2004) Protein Kinase C inhibition and X-linked inhibitor of apoptosis protein degradation contribute to the sensitization effect of 
Citation: Lu C, Xin Y, Xu Y, Zhao Z, Fu J, et al. (2011) Luteolin sensitizes Fas/FasL-induced apoptosis in HepG2 cells through inhibiting Akt Activation and promoting XIAP Degradation. J Carcinogene Mutagene 2:121. doi:10.4172/2157-2518.1000121

Page 7 of 7

Luteolin on tumor necrosis factor-related apoptosis- inducing ligand-induced apoptosis in cancer cells. Cancer Res 65: 7815-7823.

18. Horinaka M, Yoshida T, Shiraishi T, Nakata S, Wakada M, et al. (2005) The combination of TRAIL and luteolin enhances apoptosis in human cervical cancer HeLa cells. BBRC 333: 833-838.

19. Shi R, Huang Q, Zhu X, Ong YB, Zhao B, et al. (2007) Luteolin sensitizes the anticancer effect of cisplatin via c-Jun NH2-terminal kinase-mediated p53 phosphorylation and stabilization. Mol Cancer Ther 6: 1338-1347.

20. Wruck C, Claussen M, Fuhrmann G, Romer L, Schulz A, et al. (2007) Luteolin protects rat PC12 and $\mathrm{C} 6$ cells against MPP+ induced toxicity via an ERK dependent Keap1-Nrf2-ARE pathway. J Neural Transm. Suppl 72: 57-67.

21. Asselin E, Mills GB, Tsang BK (2001) XIAP Regulates Akt activity and caspase3-dependent cleavage during cisplatin-induce apoptosis in human ovarian epithelial cancer cells. Cancer Res 61: 1862-1868.

22. Strasser A and Newton K(1999). Int. J. Biochem. Cell Biol 31: 533-537.

23. Shi Y (2002) Mechanisms of caspase activation and inhibition during apoptosis Mol Cell 9: 459-470.

24. Lu B, Wang L, Stehlik C, Medan D, Huang C, et al. (2006) Phosphatidylinositol
3-Kinase/Akt Positively Regulates Fas(CD95)-Mediated Apoptosis in Epidermal Cl41 Cells. The Journal of Immunology 176: 6785-6793.

25. Jost PJ, Grabow S, Gray D, McKenzie MD, Nachbur U, et al. (2009) XIAP discriminates between type I and type II FAS-induced apoptosis. NATURE 460: 1035-1039.

26. Dan HC, Sun M, Kaneko S, Feldman RI, Nicosia SV, et al. (2004) Akt Phosphorylation and Stabilization of X-linked Inhibitor of Apoptosis Protein (XIAP). JBC 279: 5045-5412.

27. Liu Z, W. J., Yin P, Qiu J, Liu R, et al. (2009) RGD-FasL induces apoptosis in hepatocellular carcinoma. Cell Mol Immunol 6: 285-293.

28. Du GJ, Song ZH, Lin HH, Han XF, Zhang S, et al. (2008) Luteolin as glycolysis inhibitor offers superior efficacy and lesser toxicity of doxorubicin in breast cancer cells. Biochem. Biophys. Res. Commun 372: 497-502.

29. Osaki M, Oshimura M, Ito H (2004) PI3K-Akt pathway: Its functions and alterations in human cancer. Apoptosis 9: 667-676.

30. Weller M, Malipiero U, Rensing-Ehl A, Barr PJ, Fontana A (1995) Fas/APO-1 gene transfer for human malignant glioma. Cancer Res 55: 2936-2944. 